\title{
Translationally controlled tumor protein affects colorectal cancer metastasis through the high mobility group box 1-dependent pathway
}

\author{
MAOLIANG HUANG ${ }^{1,2}$, YAN GENG $^{3 *}$, QIAOTING DENG ${ }^{2}, \mathrm{RU} \mathrm{LI}^{2}, \mathrm{XIANGYANG} \mathrm{SHAO}^{2}$, \\ ZHIGAO ZHANG ${ }^{2}$, WEIWEN XU ${ }^{2}$, YINGSONG WU ${ }^{2}$ and QIANG MA ${ }^{2}$ \\ ${ }^{1}$ Fuzhou Dingxiang Clinic, Fuzhou, Fujian 350028; ${ }^{2}$ Institute of Antibody Engineering, School of Biotechnology, \\ Southern Medical University, Guangzhou, Guangdong 510515; ${ }^{3}$ Department of Intensive Care Unit, \\ 303 Hospital of Chinese People's Liberation Army, Nanning, Guanxi 530021, P.R. China
}

Received November 22, 2017; Accepted June 6, 2018

DOI: $10.3892 /$ ijo.2018.4502

\begin{abstract}
Recently, accumulating evidence from clinical and experimental researches have suggested that translationally controlled tumor protein (TCTP) and high mobility group box 1 (HMGB1) are implicated in colorectal cancer (CRC) metastasis. However, whether there is an interconnection between these two tumor-promoting proteins and how they affect CRC metastasis remain to be fully elucidated. In the present study, the expression level of TCTP in CRC tissues was assessed by immunohistochemical staining and immunoblotting, and the serum concentration of HMGB1 in patients with CRC was detected by enzyme-linked immunosorbent assay. In vitro, following the modulation of TCTP expression in colon cancer LoVo cells, the translocation behavior of HMGB1 was observed by immunofluorescence assay. Furthermore, the activity of nuclear factor- $\kappa \mathrm{B}(\mathrm{NF}-\kappa \mathrm{B})$ in LoVo cells was evaluated by immunoblotting and luciferase assay, and the invasion ability of LoVo cells after different treatments was determined using cell invasion assay. In vivo, xenograft tumor model was established and the correlation of TCTP and HMGB1
\end{abstract}

Correspondence to: Dr Qiang Ma or Professor Yingsong Wu, Institute of Antibody Engineering, School of Biotechnology, Southern Medical University, 1838 North Guangzhou Avenue, Guangzhou, Guangdong 510515, P.R. China

E-mail: mq@smu.edu.cn

E-mail:wg@smu.edu.cn

${ }^{*}$ Contributed equally

Abbreviations: CRC, colorectal cancer; TCTP, translationally controlled tumor protein; HMGB1, high mobility group box 1 ; NF- $\kappa \mathrm{B}$,

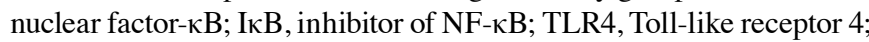
RAGE, receptor for advanced glycation end products; ELISA, enzyme-linked immunosorbent assay; $\mathrm{LDH}$, lactate dehydrogenase

Key words: colorectal cancer, translationally controlled tumor protein, high mobility group box 1 , nuclear factor- $\mathrm{\kappa} \mathrm{B}$, tumor metastasis expression in xenografted tumors was studied by immunohistochemical examination. The results revealed that the expression level of TCTP in CRC tissue and the serum concentration of HMGB1 in patients with CRC were significantly increased, and there was a strong positive correlation between them. In vitro experiments showed that the overexpression of TCTP on LoVo cells resulted in the release of HMGB1 from the nucleus to the cytoplasm and into the extracellular space. In addition, the overexpression of TCTP led to the activation of NF- $\kappa \mathrm{B}$ in LoVo cells, and this effect was reversed by treatment with antibodies targeting HMGB1 or to its receptors Toll-like receptor 4 (TLR4) and receptor for advanced glycation end products advanced glycation end products (RAGE). Furthermore, inhibition of the HMGB1-TLR4/RAGE-NF- $\kappa$ B pathway significantly inhibited the TCTP-stimulated invasion of LoVo cells. In vivo experiments demonstrated that the overexpression of TCTP in nude mice promoted the development and spread of xenografted tumors, and concurrently enhanced the expression of HMGB1 in tumor tissues. Collectively, these findings suggested that TCTP promotes CRC metastasis through regulating the behaviors of HMGB1 and the downstream activation of the NF- $\kappa \mathrm{B}$ signaling pathway.

\section{Introduction}

Colorectal cancer (CRC) is one of the most frequent malignant diseases in the world. The metastatic spread of CRC is a crucial factor for the progression and therapeutic management of the disease. Due to the lack of suitable biomarkers for early diagnosis and specific targets for precise treatment, the general prognosis of late-stage CRC remains poor. Currently, the 5-year relative survival rate for metastatic CRC is only $\sim 10 \%$ (1). Therefore, the pursuit of early diagnosis markers and novel therapeutic targets is imperative for improving the outcome of these patients.

A substantial body of evidence demonstrates that translationally controlled tumor protein (TCTP), a highly conserved and multifunctional protein, is implicated in the tumorigenesis of various malignances (2-4). The expression levels of TCTP are frequently elevated in human cancer, and a high 
TCTP status has been associated with a poor outcome in mammary (5), hepatocellular (6) and colorectal cancer (7).

In our previous studies, it was demonstrated that TCTP is involved in CRC progression and metastasis $(7,8)$, and a possible mechanism was suggested, in which TCTP may induce activation of the cell division cycle 42 (Cdc42)/c-Jun N-terminal kinase/matrix metalloproteinase (MMP)9 signaling pathway (7), which is closely associated with the invasion and metastatic potential of tumors. However, tumor metastasis is a complex system in which several factors are involved and interconnected to form a large and complex network. Our previous findings may explain certain aspects of the role of TCTP in tumor metastasis, however, whether there is any relevant influential factor that it is important in this metastatic process remains to be elucidated and requires further investigation.

In our previous proteome experiment, it was determined that several important proteins were markedly altered following the knockdown of TCTP (8). Among them, high mobility group box 1 (HMGB1) was of particular interest, as accumulating evidence suggests that HMGB1 is overexpressed in CRC tissue and also contributes to tumor growth and metastasis (9-11). Therefore, it was hypothesized that there may be an important interaction between TCTP and HMGB1 in the tumor metastasis process.

As is known at present, HMGB1 is one of the non-histone chromosomal proteins and also an extracellular damageassociated molecular pattern molecule. It locates in the nucleus where it binds to minor groove DNA, and functions as a regulator of gene transcription. During states of cellular stress or damage, HMGB1 can be released from cells and become an extracellular cytokine, being involved in inflammation, angiogenesis, cell proliferation and migration (12-14). Toll-like receptors (TLRs) and receptor for advanced glycation end products (RAGE) are the main receptors of HMGB1 $(15,16)$. Although signaling pathways for the two receptor groups are different, ultimately, they both activate nuclear factor- $\kappa \mathrm{B}(\mathrm{NF}-\kappa \mathrm{B})(12,17-19)$. NF- $\mathrm{NB}$ is an inducible dimeric transcription factor, and its prototype in the majority of cell types is the p65/p50 heterodimer. It is usually retained in an inactive state in the cytoplasm by its association with inhibitor of $\mathrm{NF}-\kappa \mathrm{B}(\mathrm{I} \kappa \mathrm{B})$. Upon stimulation, $\mathrm{I} \kappa \mathrm{B} \alpha$ is rapidly phosphorylated and subsequently degraded by proteasomes, permitting translocation of the p65/p60 heterodimer into the nucleus. This results in the activation of target genes associated with cell proliferation, inflammation, and tumor development and metastasis $(20,21)$.

On the basis of the above knowledge, it was hypothesized that TCTP may promote CRC metastasis through regulating the expression and secretion of HMGB1 and consequent activation of the NF- $\mathrm{KB}$ signaling pathway. The present study aimed to provide experimental evidence to confirm this hypothesis.

\section{Materials and methods}

Materials. Primary antibodies specific for TCTP (sc-133131), TLR4 (sc-293072), RAGE (sc-365154), NF-кB p65 (sc-8008), $\mathrm{I} \kappa \mathrm{B} \alpha$ (sc-1643), GAPDH (sc-32233) and Lamin B (sc-374015), secondary anti-mouse (sc-2005) and anti-rabbit (sc-2030) IgG-conjugated horseradish peroxidase, and the specific
$\mathrm{NF}-\kappa \mathrm{B}$ inhibitor Bay117082 were purchased from Santa Cruz Biotechnology, Inc. (Santa Cruz, CA, USA). Antibody specific for HMGB1 (ab18256) was obtained from Abcam (Cambridge, MA, USA). The recombinant human HMGB1 (rhHMGB1) and all other chemicals were supplied by Sigma-Aldrich; EMD Millipore (Billerica, MA, USA).

Clinical samples. The present study recruited 30 patients who were endoscopically diagnosed and histologically confirmed with CRC and then admitted to Nanfang Hospital, Southern Medical University (Guangzhou, China) between September, 2016 and August, 2017. Among these patients, 21 were men and nine were women, with a mean age of 58.6 years, and 12 patients $(40 \%)$ were confirmed to have distant metastases by histopathological examination of surgical specimens or by imageological detection. Additionally, 10 individuals with benign colorectal polyps were enrolled as controls (six men and four women, mean age 52.5 years). Peripheral blood samples were obtained from all participants prior to any treatment and stored at $-80^{\circ} \mathrm{C}$ until analysis. The colorectal specimens were obtained following tumor excision or endoscopic polypectomy. The protocols for the collection of human tissues were approved by the Ethics Committee of Nanfang Hospital, Southern Medical University, and written informed consent was signed by each participant prior to their inclusion in the study.

Immunohistochemical examination. Tissue sections ( $3 \mu \mathrm{m}$ thickness) were deparaffinized in histolene and hydrated in graded ethanol. Endogenous peroxidase activity was quenched by treating the sections with $3 \%$ hydrogen peroxide in phosphate-buffered saline (PBS) for $10 \mathrm{~min}$. The primary antibody against TCTP or HMGB1 (both at a dilution of 1:1,000) was applied overnight at $4^{\circ} \mathrm{C}$. The sections were then incubated for $30 \mathrm{~min}$ with the secondary antibody $(1: 1,000)$ at room temperature. Finally, the sections were developed by applying diaminobenzidine as a chromogen, followed by counterstaining with hematoxylin. Sections incubated without primary antibody served as negative controls. The slides were semi-quantitatively scored using a Nikon Eclipse E100 microscope (Nikon Instruments, Tokyo, Japan), according to the mean density (the ratio of the integral optical density to the total area), as previously described (7). The mean percentage of positive cells was classified into four categories: 0 for negative, 1 (weak) for $<10 \%, 2$ (moderate) for $10-50 \%$, and 3 (strong) for $>50 \%$.

Enzyme-linked immunosorbent assay (ELISA). The HMGB1 concentrations in serum samples were quantified by means of an HMGB1 ELISA Kit II (Shino-Test, Tokyo, Japan) according to the manufacturer's protocol. Briefly, the standard, sample or control was added to 96 -well microtiter plates and incubated for $24 \mathrm{~h}$ at $37^{\circ} \mathrm{C}$. Following washing, anti-HMGB1 peroxidaseconjugated monoclonal antibody was added and incubated at room temperature for $2 \mathrm{~h}$. The plates were washed again and a substrate solution was added. The enzyme colorimetric reaction was allowed to proceed for $30 \mathrm{~min}$ at room temperature and terminated by the addition of stop solution. The absorbance was read at $450 \mathrm{~nm}$, and results were calculated using a calibration curve prepared from the standards. 
Cell culture. Human colon adenocarcinoma LoVo cells, obtained from American Type Culture Collection (Rockville, MD, USA), were plated on culture flasks and cultured in Dulbecco's modified Eagle's medium (DMEM; Gibco; Thermo Fisher Scientific, Inc., Waltham, MA, USA) supplemented with $10 \%$ inactivated fetal bovine serum (FBS), 2 mM L-glutamine (both from Invitrogen; Thermo Fisher Scientific, Inc.), and 1\% penicillin/streptomycin (Gibco; Thermo Fisher Scientific, Inc.) in a humidified incubator at $37^{\circ} \mathrm{C}$ and $5 \% \mathrm{CO}_{2}$.

Protein preparation. Total proteins were extracted from the tissues with RIPA lysis buffer (Beyotime Institute of Biotechnology, Jiangsu, China) containing protease inhibitors, whereas nuclear and cytoplasmic extracts from LoVo cells were prepared using a Nuclear and Cytoplasmic Protein Extraction kit (Beyotime Institute of Biotechnology). For preparation of the protein in the cell culture medium, an ultrafiltration method was used, as described previously (22). Briefly, the cells in a $100-\mathrm{mm}$ plate were washed and incubated in serum-free medium for $24 \mathrm{~h}$. Following the elimination of cellular debris by $10 \mathrm{~min}$ of centrifugation at $3,000 \mathrm{x} \mathrm{g}$ at $4^{\circ} \mathrm{C}$, the culture medium was concentrated to $100 \mu \mathrm{l}$ with an Amicon Ultra-15 centrifugal filter (EMD Millipore, Burlington, MA, USA).

Immunoblotting. The protein concentration of samples was detected by Pierce BCA Protein Assay Kit (Thermo Fisher Scientific, Inc.), according to the manufacturer's instructions. Samples containing the same quantity of protein $(20 \mu \mathrm{g})$ were separated by sodium dodecyl sulfate-polyacrylamide gel electrophoresis with $12 \%$ gels and were electroblotted onto polyvinylidene difluoride membranes. Following transfer, the membranes were blocked with 5\% non-fat milk in Tris-buffered saline-Tween and then incubated overnight at $4^{\circ} \mathrm{C}$ with the different primary antibodies (specific for TCTP, $\mathrm{I} \kappa \mathrm{B} \alpha, \mathrm{NF}-\kappa \mathrm{B}$ p65, GAPDH and Lamin B, respectively) at a dilution of 1:200, with the exception of anti-HMGB1 used at a dilution of 1:1,000, followed by incubation with the horseradish peroxidase-conjugated secondary antibodies $(1: 1,000)$ at room temperature for $1 \mathrm{~h}$. The immunoreactive bands were detected with an enhanced chemiluminescence system (Pierce; Thermo Fisher Scientific, Inc.). The density of individual bands was quantified by densitometric scanning of the blots using ImageJ software version 1.45 (NIH, Bethesda, MD, USA).

Immunofluorescence assay. The cells $\left(5 \times 10^{6} / \mathrm{ml}\right)$ were placed on Matrigel-coated cover slides. After $24 \mathrm{~h}$, cells on the cover slides were fixed with paraformaldehyde and permeabilized with $0.2 \%$ Triton X-100. The slides were blocked with $10 \%$ bovine serum albumin (Sigma-Aldrich, St. Louis, MO, USA) in PBS for $1 \mathrm{~h}$ and then incubated with rabbit anti-HMGB1 antibody (1:200) at $4^{\circ} \mathrm{C}$ for $24 \mathrm{~h}$. Following washing with PBS, the cells were incubated with fluorescence-conjugated goat anti-rabbit IgG (A11008; Invitrogen; Thermo Fisher Scientific, Inc.) at room temperature for $30 \mathrm{~min}$ and then incubated with Hoechst 33258 (Beyotime Institute of Biotechnology) for $10 \mathrm{~min}$. The cells were then rinsed in PBS, and viewed under a fluorescent microscope.

Construction of short hairpin (sh)RNA plasmid targeting TCTP. The RNA interference experiment protocol was performed as previously described (8). Nucleotides 228-246 (CTCGCTCATTGGTGGAAAT) of the TCTP (GenBank accession no. NM003295) coding sequence was selected as the target for shRNA. The shRNA-TCTP encoding sequence was created by using two complementary oligonucleotides, each containing the 19-nucleotide target sequence of TCTP(228-246), followed by a short spacer (TTCAAGAGA). The shRNA TCTPencoding sequence was cloned into the BamHI and BbsI sites of the pGPU6/GFP/Neo siRNA expression vector (GenePharma, Shanghai, China).

Construction of plasmid overexpressing TCTP. Primers were designed to amplify the coding region of TCTP as follows: Forward, GAAGATCTATGATTATCTACCGGGACCTCAT (BglII) and reverse, GGAATTCTTAACATTTTTCCATTTCT AAACCA (EcoRI). The pEGFP-C1-TCTP was constructed and verified by sequencing the inserted gene. The plasmid was transfected into cells with Lipofectamine 2000 ${ }^{\mathrm{TM}}$ (Invitrogen; Thermo Fisher Scientific, Inc.), according to the manufacturer's protocol. Stable transfectants were selected using G418 (Gibco; Thermo Fisher Scientific, Inc.), and the GFP signal was visualized under a laser-scanning confocal microscope.

Lactate dehydrogenase $(\mathrm{LDH})$ assay. The levels of LDH released into the culture medium were determined using an LDH assay kit (Sigma-Aldrich; EMD Millipore) in accordance with the manufacturer's protocol. The cell culture supernatants were collected by centrifugation at $300 \mathrm{x}$ g for $5 \mathrm{~min}$ at room temperature, followed by transfer onto 96 -well plates. The plates were treated with reaction solution and placed in the dark for $30 \mathrm{~min}$ at room temperature. The absorbance was measured at $490 \mathrm{~nm}$ in an automatic microplate reader, subtracting the corresponding background values from all samples.

Cell invasion assay. Cell invasion assays were performed using Costar ${ }^{\circledR}$ Transwell $^{\mathrm{TM}}$ Permeable Supports (Corning Incorporated, Corning, NY, USA). The cells $\left(2 \times 10^{5}\right)$ were suspended in DMEM supplemented with $0.1 \%$ FBS and added to the upper chamber. The lower chamber contained $500 \mu \mathrm{l}$ of DMEM with $10 \%$ FBS, and the polycarbonate filter was coated with $40 \mu \mathrm{l}$ of Matrigel (R\&D Systems, Inc., Wiesbaden, Germany). Following $24 \mathrm{~h}$ of incubation at $37^{\circ} \mathrm{C}$, the cells on the upper surface of the filter were removed by wiping with a cotton swab. The filters were fixed in $4 \%$ paraformaldehyde and were stained with crystal violet. Those cells that migrated to the lower surface of the filter were counted based on six fields randomly under an EVOS FL Auto fluorescence microscope (Invitrogen; Thermo Fisher Scientific, Inc.) at x400 magnification.

Luciferase assay. The LoVo cells were seeded in 24-well plates at $1 \times 10^{5}$ cells per well. The cells were transiently co-transfected with $400 \mathrm{ng}$ of pNF-кB-Luc (Clontech Laboratories, Inc., Mountain View, CA, USA) and 4 ng of pRL-SV40 (Promega, Madison, WI, USA) using Lipofectamine $2000^{\mathrm{TM}}$ (Invitrogen). The pRL-SV40 plasmid with a cDNA encoding Renilla luciferase was used as an internal control. The cell extracts were prepared in luciferase cell culture lysis buffer (Promega). The activities of firefly and Renilla luciferases were measured 
A
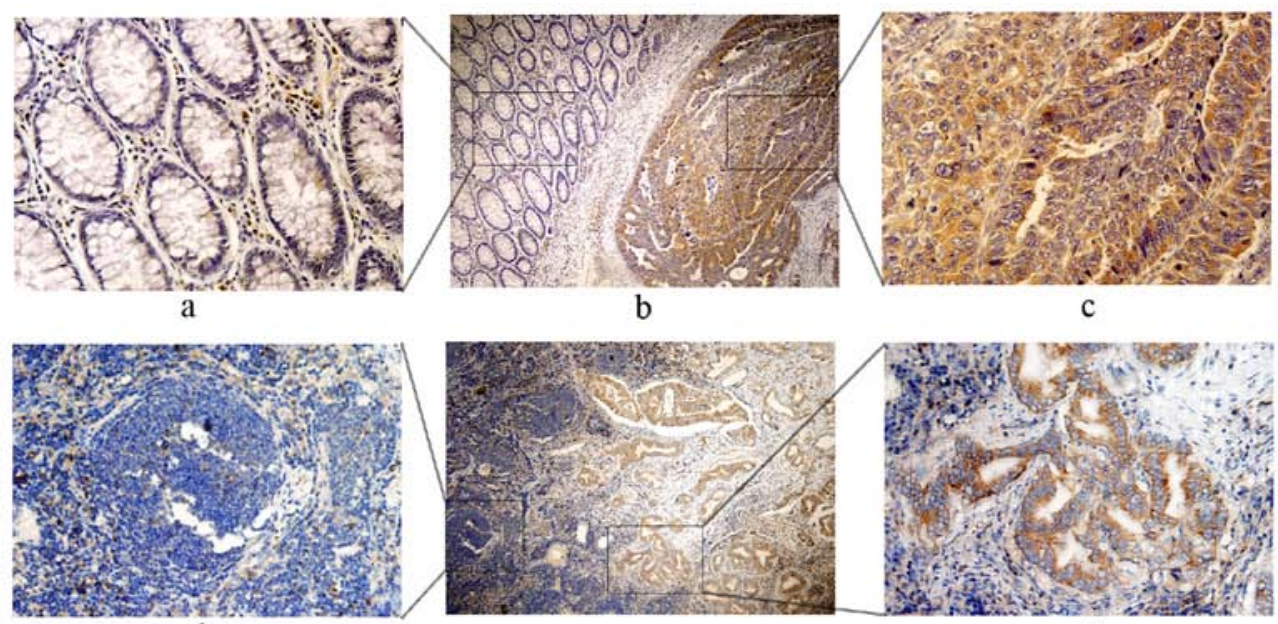

d

e

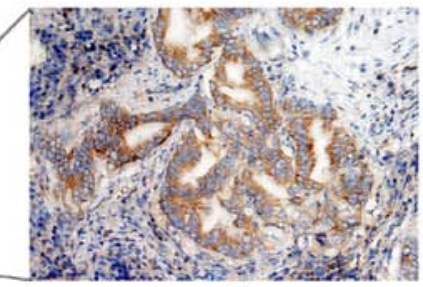

$\mathrm{f}$

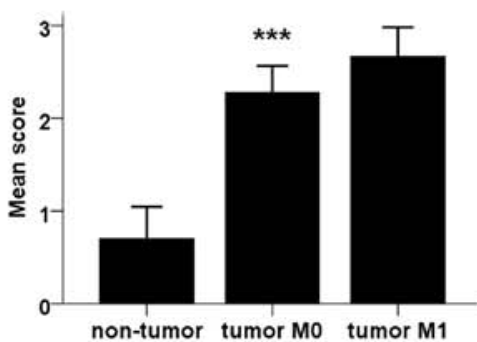

B

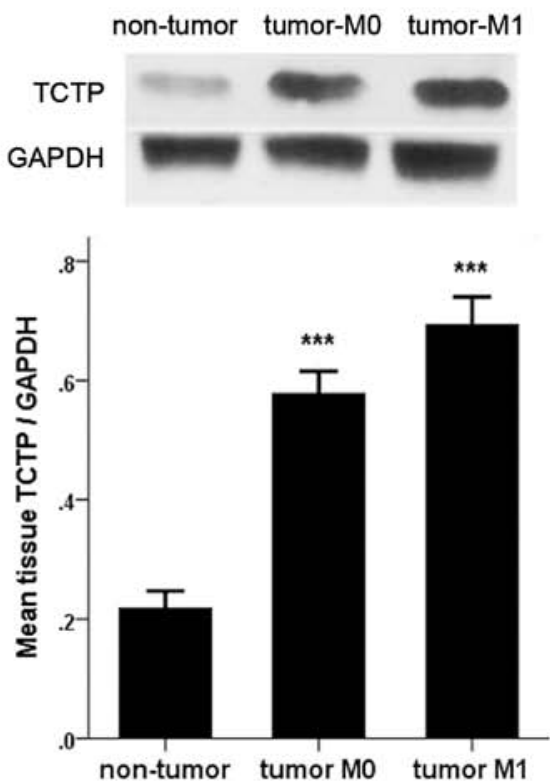

C

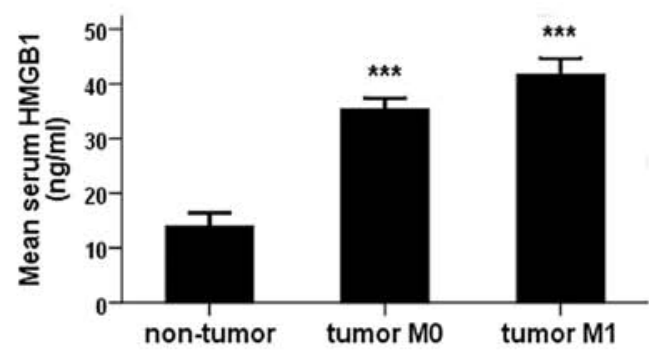

D

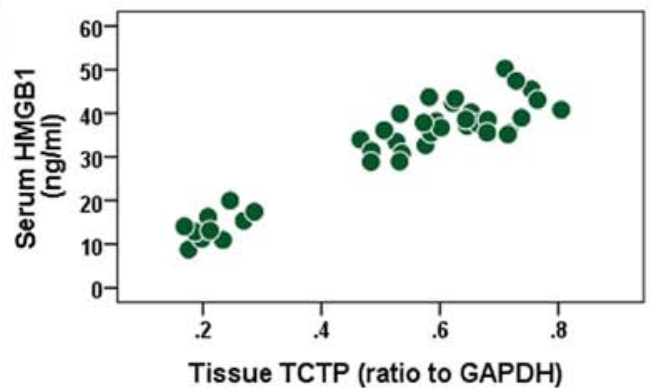

Figure 1. Detection of the histological expression of TCTP and serum value of HMGB1 in patients with CRC. (A) Immunohistochemical detection of expression of TCTP in CRC tissues (upper panel) and metastatic lymph nodes (lower panel) and the adjacent normal tissues. Specific TCTP staining is shown in brown. Panels a, c, $d$ and f, show a magnification of $x 400$; panels $b$ and e show a magnification of $x 100$. Panels a, $c, d$ and $f$ are amplifications of the marked (with squares) areas shown in panels $\mathrm{b}$ and e, respectively $\left({ }^{* * * *} \mathrm{P}<0.001\right.$ between $\mathrm{CRC}$ and non-tumor groups). (B) Immunoblot analysis of expression of TCTP in colorectal samples from patients with CRC or from control subjects with benign polyps (non-tumor). Values were normalized to the internal control GAPDH $\left({ }^{* * *} \mathrm{P}<0.001\right.$ between each two groups). (C) Enzyme-linked immunoassay examination of serum levels of HMGB1 in patients with CRC and control subjects (non-tumor) ${ }^{* * *} \mathrm{P}<0.001$ between each two groups). (D) Correlation plot generated with serum HMGB1 values and tumor tissue TCTP expression in 30 patients with CRC and 10 non-cancerous controls (Pearson's correlation coefficient, $0.935 ; \mathrm{P}<0.001$ ). CRC, colorectal cancer; TCTP, translationally controlled tumor protein; HMGB1, high mobility group box 1; M0, no metastasis; M1, metastasis.

sequentially from a single sample with the Dual Luciferase Reporter Assay system (Promega) using a Lumat LB 9507 luminometer (Bethold Technologies, Bad Wildbad, Germany).

Tumor xenografts. Male BALB/c nude mice ( $\mathrm{n}=6$ each group), aged from 6 to 8 weeks and weighing approximately $18-22 \mathrm{~g}$, were supplied by the Laboratory Animal Center of Southern Medical University (Guangzhou, China). All mice were bred under specific pathogen-free conditions, at light periods of $12 \mathrm{~h}$ each day, and were fed water and mouse chow ad libitum. The experiment was approved by the Association for the Accreditation and Assessment of Laboratory Animal Care 
A
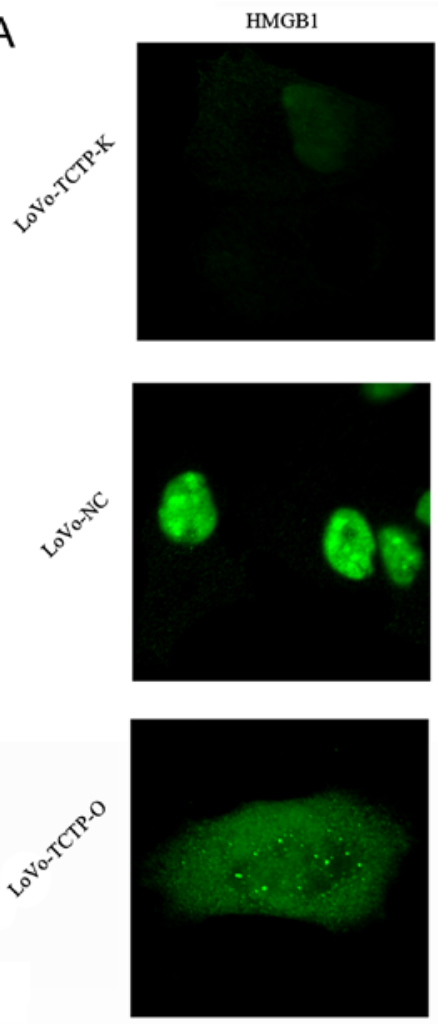

Actin
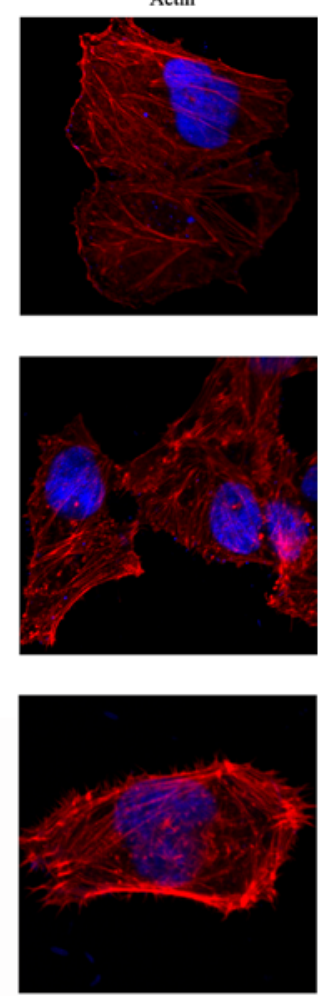
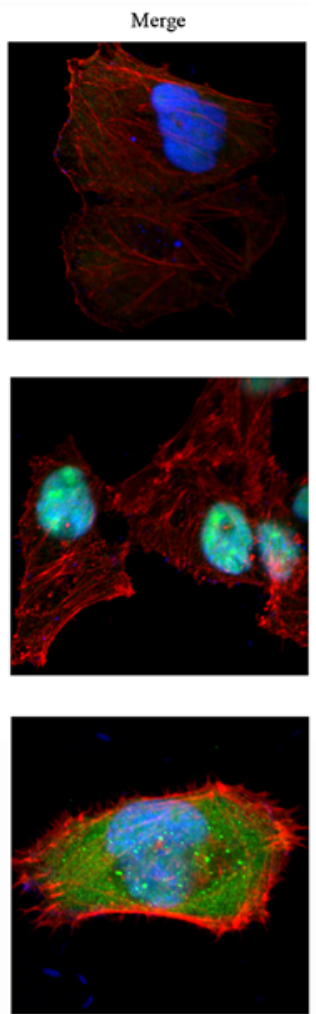
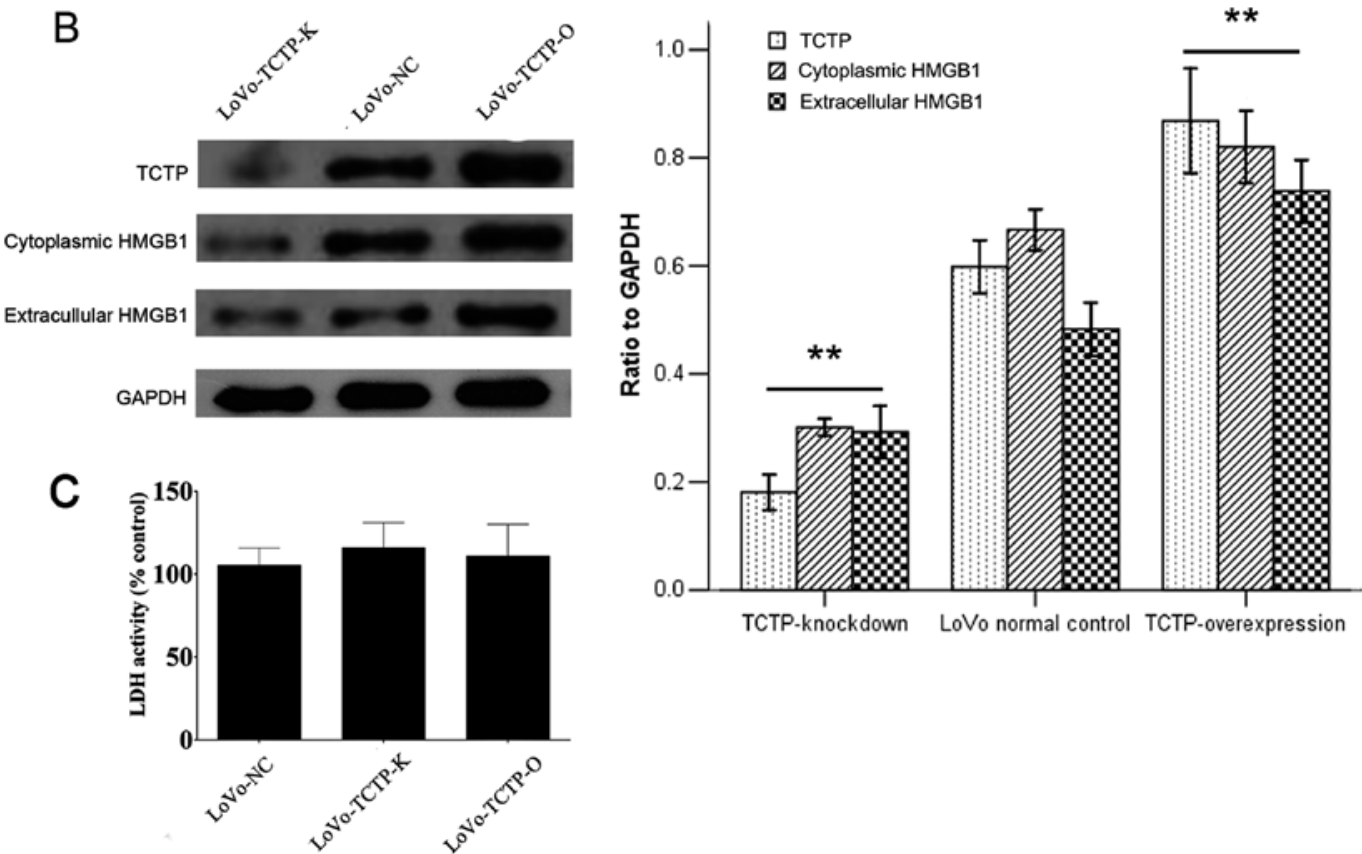

Figure 2. Effect of TCTP on the expression and secretion of HMGB1 in LoVo cells. (A) Immunofluorescence analysis of the expression of HMGB1 following modulation of the expression of TCTP in LoVo cells (magnification, x400). Green, HMGB1; blue, nuclei; red, F-actin. (B) Immunoblotting analysis of the expression of HMGB1 in the cytoplasm and the culture medium of LoVo cells following modulation of the expression of TCTP. Values were normalized to the internal control GAPDH. ${ }^{* *} \mathrm{P}<0.01$, compared with LoVo-NC cells. Similar results were obtained in four independent experiments. (C) Measurement of extracellular LDH release from control LoVo cells or cells transfected with vectors. The results are expressed as a percentage relative to the control group. No significant difference was observed in LDH activity among the three cell lines. LoVo-NC, normal control LoVo cells; TCTP-K, LoVo cells transfected with TCTP-knockdown vector; TCTP-O, LoVo cells transfected with TCTP-overexpression vector; TCTP, translationally controlled tumor protein; HMGB1, high mobility group box $1 ; \mathrm{LDH}$, lactate dehydrogenase.

(Guangzhou, China). To produce the experimental liver metastasis model, LoVo cells $\left(5 \times 10^{6}\right)$ were injected into the spleen of nude mice, as described previously $(7,8)$. Following 5 weeks of inoculation, the mice (weighing from 28 to $39 \mathrm{~g}$ ) were sacrificed and the tumors were collected. The number of macroscopically visible metastatic nodules on the surface of liver was counted. The tumor specimens from primary or metastatic sites were used for histological examinations and immunohistochemical assays. 


$\begin{array}{rrrr}\text { LoVo-NC } & + & + & + \\ \text { TCTP-O } & - & + & + \\ \text { anti-HMGB1 } & - & - & +\end{array}$

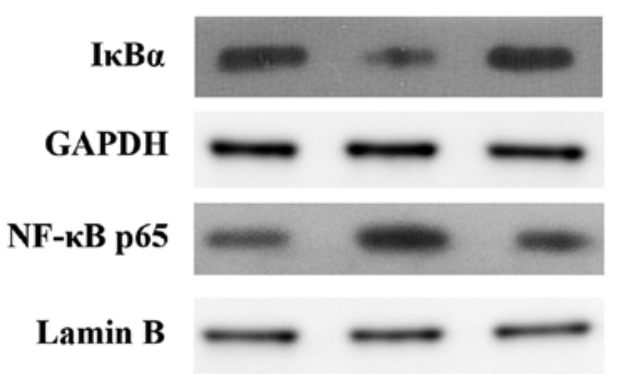

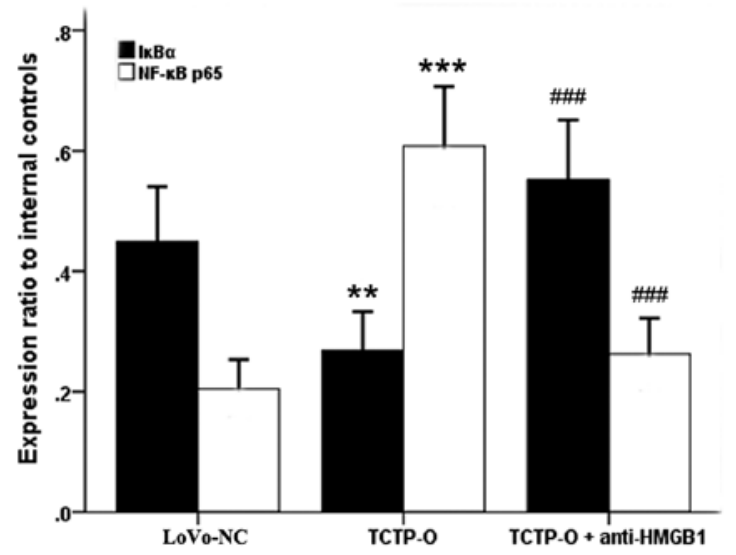

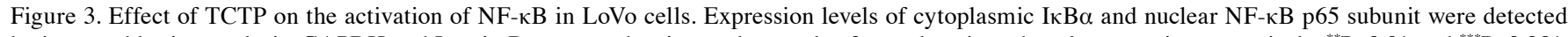
by immunoblotting analysis. GAPDH and Lamin B were used as internal controls of cytoplasmic and nuclear protein, respectively. ${ }^{* *} \mathrm{P}<0.01$ and ${ }^{* * * *} \mathrm{P}<0.001$, compared with the LoVo-NC cells; ${ }^{\# \# \#} \mathrm{P}<0.001$, between the TCTP-O cells with and without anti-HMGB. Similar results were obtained in four independent experiments. LoVo-NC, normal control LoVo cells; TCIP-O, LoVo cells transfected with TCTP-overexpression vector; TCTP, translationally controlled tumor

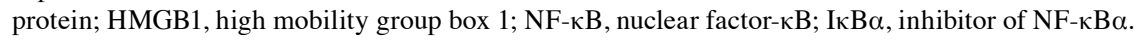

A
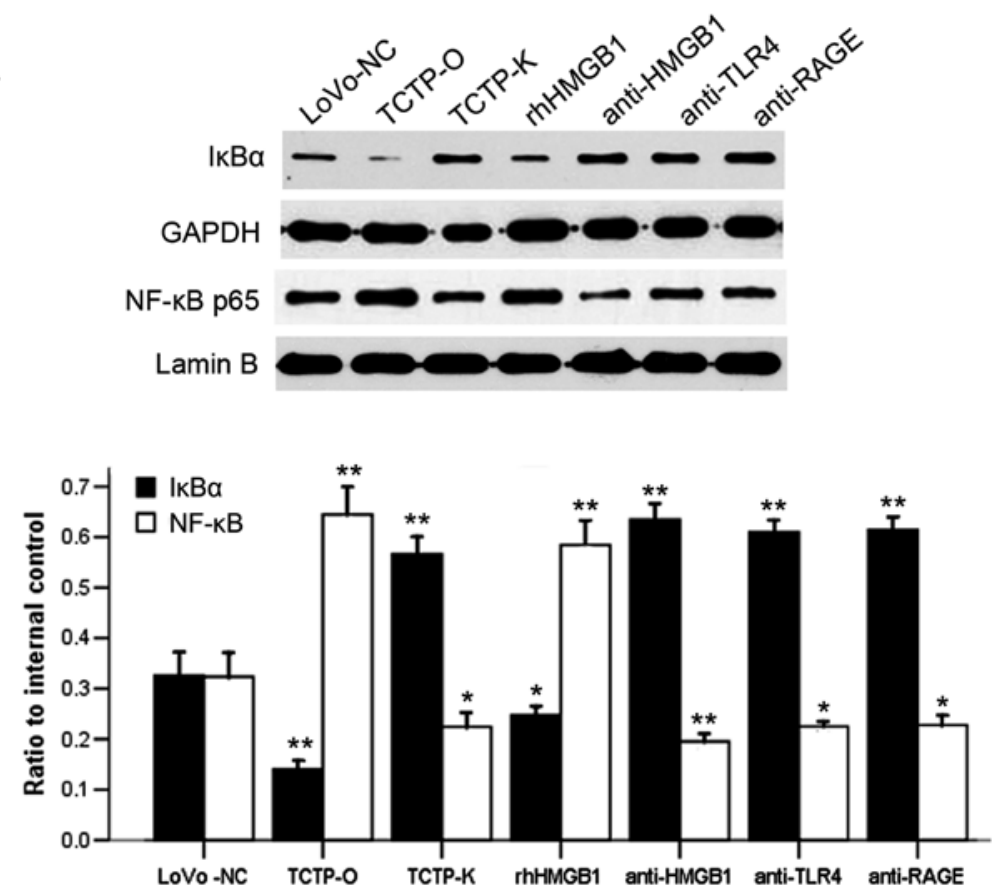

B

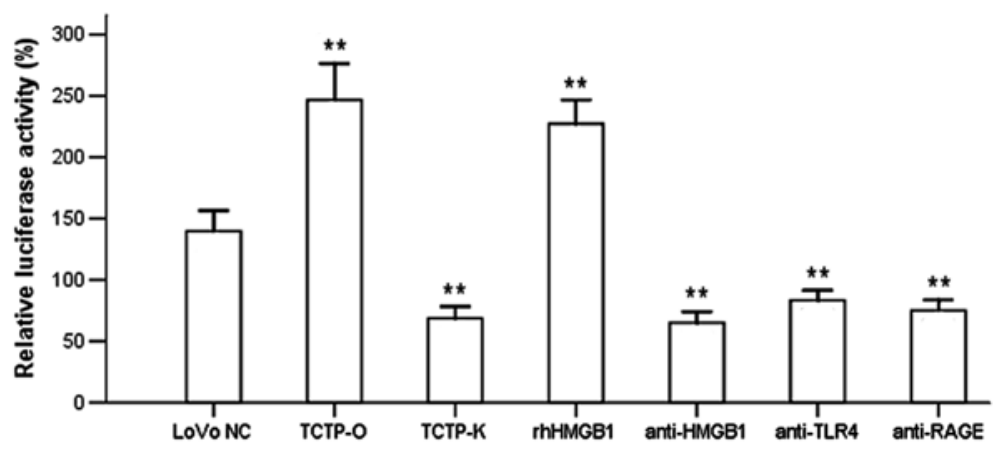

Figure 4. Effect of antibodies against HMGB1 or its receptors TLR4 and RAGE on the TCTP-induced activation of NF- $\mathrm{kB}$ in LoVo cells. (A) Immunoblotting

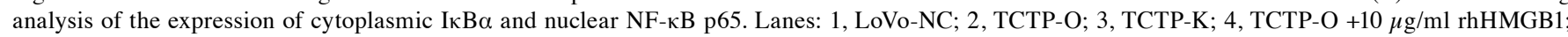
5, TCTP-O $+5 \mu \mathrm{g} / \mathrm{ml}$ anti-HMGB1; 6, TCTP-O $+5 \mu \mathrm{g} / \mathrm{ml}$ anti-TLR4; 7, TCTP-O $+5 \mu \mathrm{g} / \mathrm{ml}$ anti-RAGE. GAPDH and Lamin B were used as internal controls of cytoplasmic and nuclear protein, respectively. ${ }^{*} \mathrm{P}<0.05$ and ${ }^{* *} \mathrm{P}<0.01$, compared with LoVo-NC cells. Data are the representative of four experiments with similar results. (B) Activity of NF- $\mathrm{kB}$ was determined by a Luciferase reporter assay. ${ }^{* *} \mathrm{P}<0.01$, compared with LoVo-NC cells. Each assay was performed in triplicate. LoVo-NC, normal control LoVo cells; TCTP-K, LoVo cells transfected with TCTP-knockdown vector; TCTP-O, LoVo cells transfected with TCTP-overexpression vector; TCTP, translationally controlled tumor protein; HMGB1, high mobility group box 1; rhHMGB1, recombinant human HMGB1;

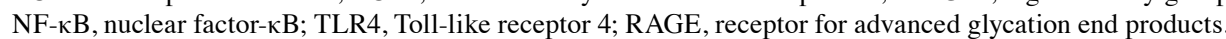




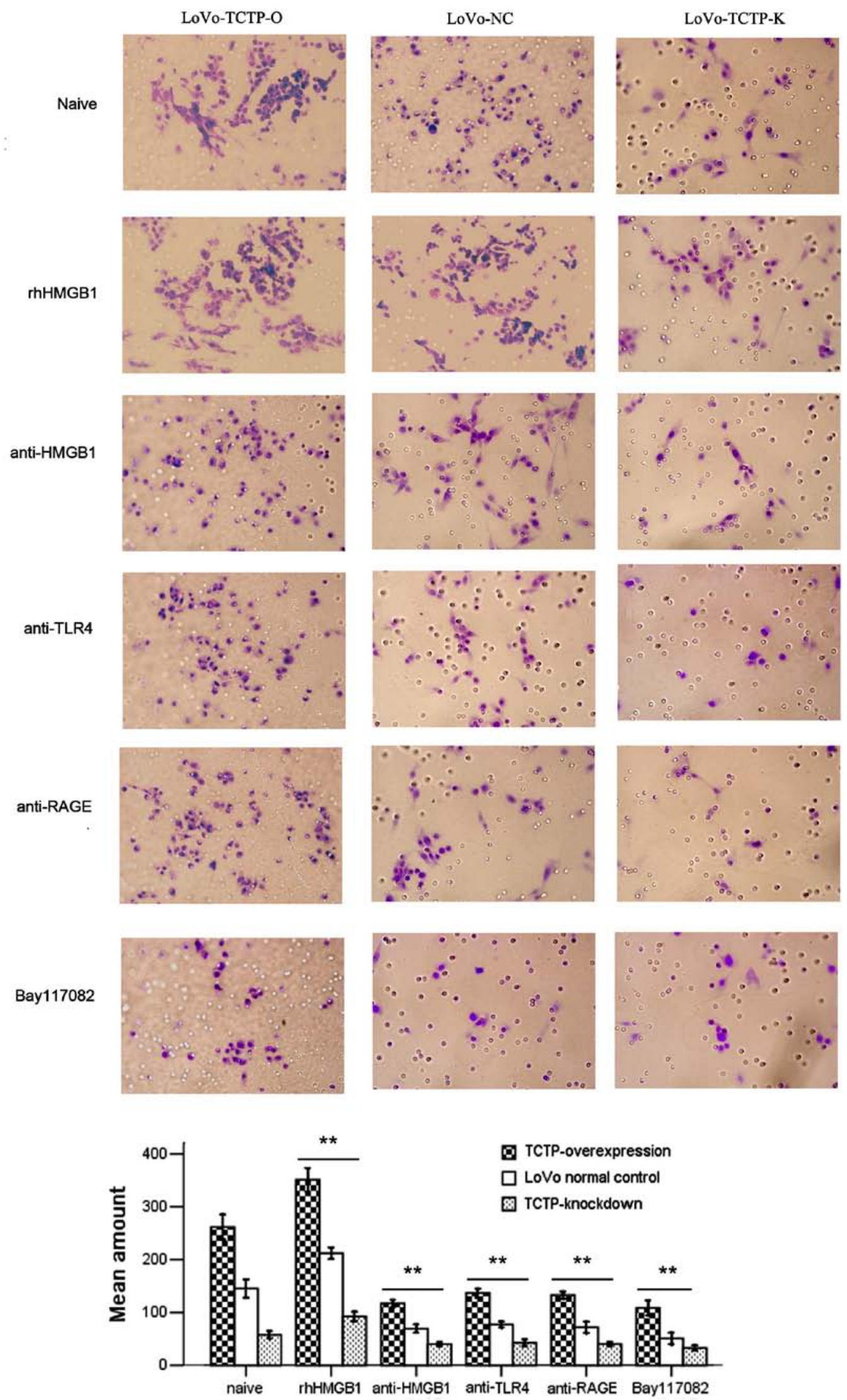

Figure 5. Effect of TCTP and the HMGB1-TLR4/RAGE-NF- $\mathrm{kB}$ pathway on the invasion potential of LoVo cells (magnification, $\mathrm{x} 400$ ). The invasive capacity of LoVo NC cells (middle), LoVo TCTP-O cells (left) or LoVo-TCTP-K (right) were assessed by a cell invasion assay. The number of invasive cells was quantified by visual counting of six randomly selected fields. The groups comprised cells left untreated as controls, cells treated with rhHMGB1 (10 $\mu \mathrm{g} / \mathrm{ml})$ or anti-HMGB1, anti-TLR4, anti-RAGE (all $5 \mu \mathrm{g} / \mathrm{ml})$ or the specific NF- $\mathrm{KB}$ inhibitor Bay117082 $(5 \mu \mathrm{mol} / \mathrm{l})$, respectively. ${ }^{* *} \mathrm{P}<0.01$, compared with untreated cells. Similar results were obtained in four independent experiments. LoVo-NC, normal control LoVo cells; TCTP-K, LoVo cells transfected with TCTP-knockdown vector; TCTP-O, LoVo cells transfected with TCTP-overexpression vector; TCTP, translationally controlled tumor protein; HMGB1, high mobility group

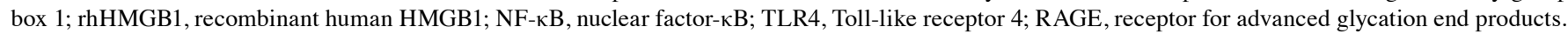


A

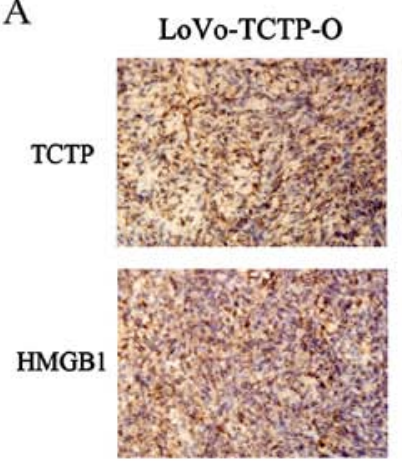

B

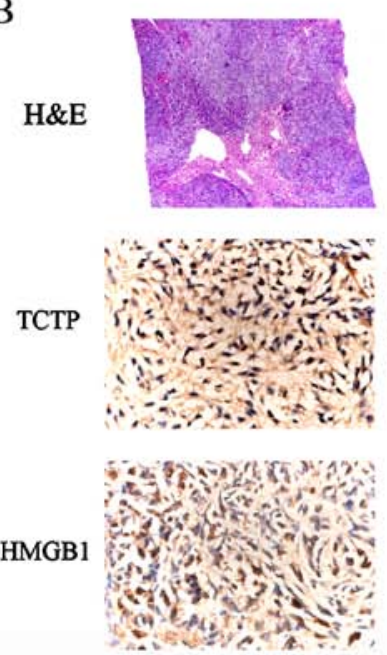

LoVo-TCTP-NC
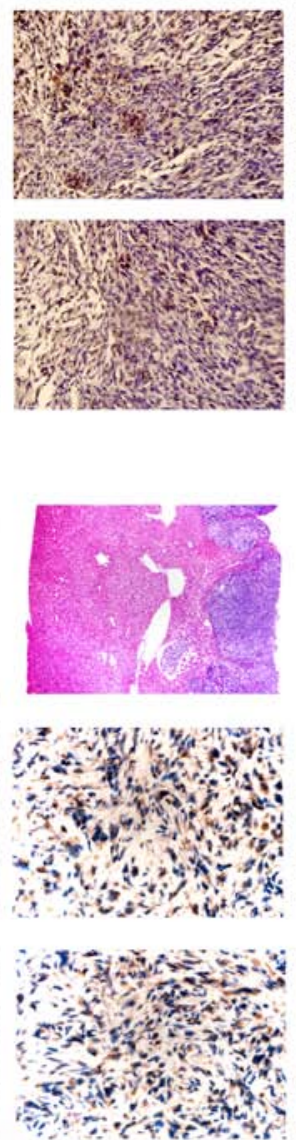
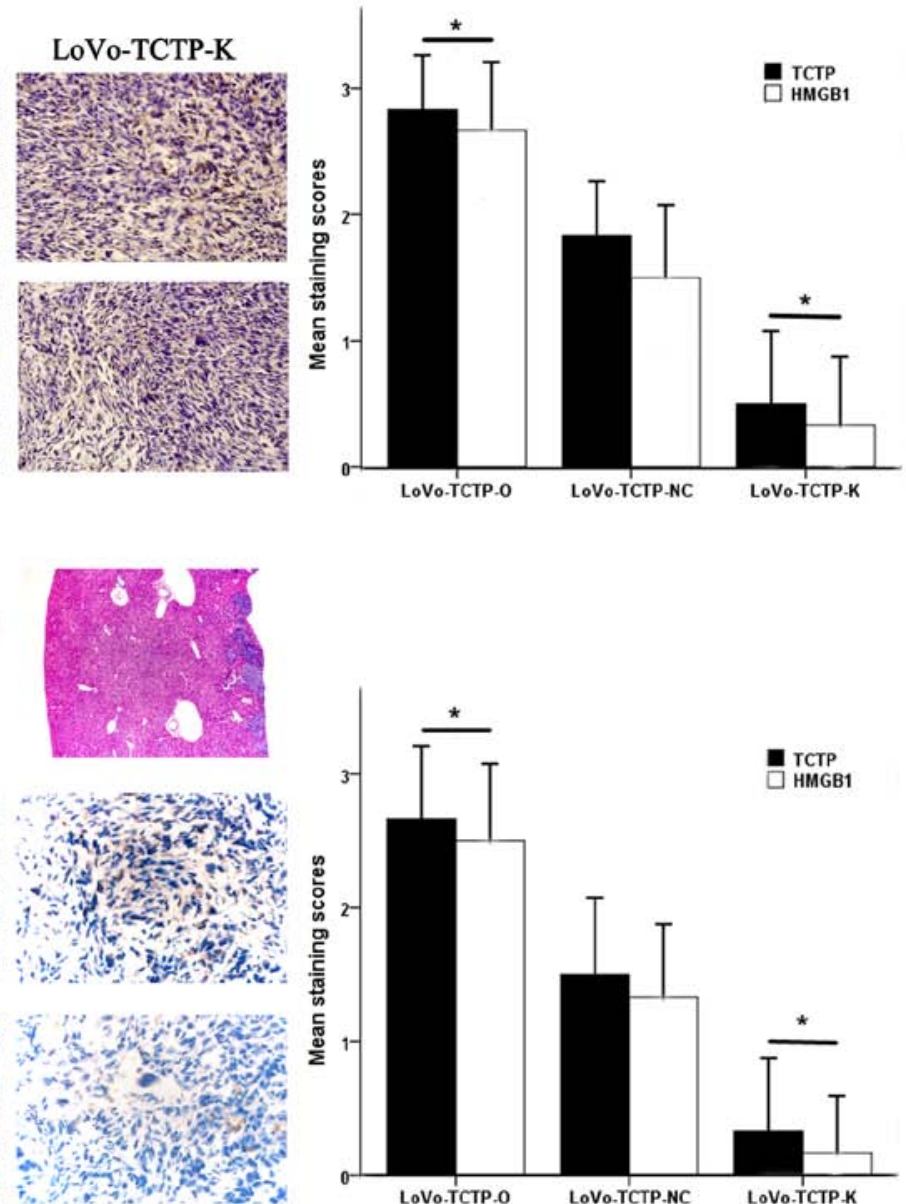

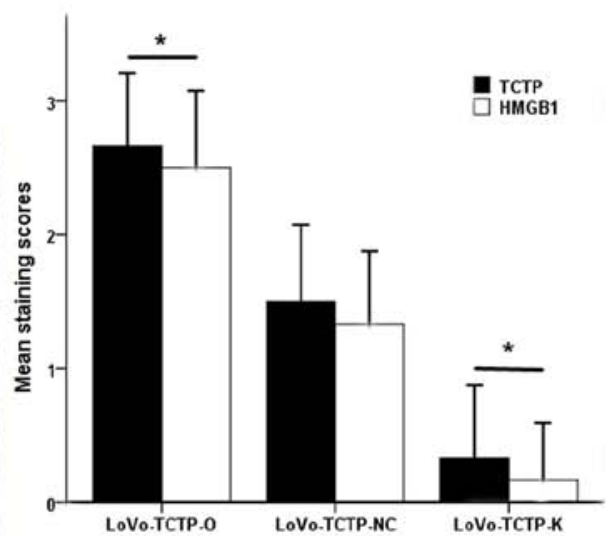

Figure 6. Effect of TCTP on the expression of HMGB1 in xenograft tumors in nude mice. (A) Expression of TCTP and HMGB1 in the developed tumors in the nude mouse spleen were detected 5 weeks following inoculation with LoVo cells (magnification, $\mathrm{x} 400$ ). ${ }^{*} \mathrm{P}<0.05$, compared with mice receiving normal control LoVo cells. (B) Expression of TCTP and HMGB1 in metastatic tumors in the nude mouse liver were detected 5 weeks following inoculation with LoVo cells (magnification, $\mathrm{x} 400$ ). ${ }^{*} \mathrm{P}<0.05$, compared with mice receiving normal control LoVo cells. The H\&E panel shows sections of liver stained with H\&E (magnification, x100). TCTP-NC, normal control LoVo cells; TCTP-K, LoVo cells transfected with TCTP-knockdown vector; TCTP-O, LoVo cells transfected with TCTP-overexpression vector; TCTP, translationally controlled tumor protein; HMGB1, high mobility group box 1; H\&E, hematoxylin and eosin.

Statistical analysis. All data are expressed as the mean \pm standard deviation. Multiple comparisons were performed using one-way analysis of variance (ANOVA) or nested ANOVA with the Bonferroni test or Dunnett's T3 test, depending on whether equal variances could be assumed. The non-parametric Kruskal-Wallis test was used for the comparison of the immunohistochemical staining scores. Pearson's correlation coefficient was used to measure the association between detected values of TCTP and HMGB1. P $<0.05$ was considered to indicate a statistically significant difference. All statistical analyses were performed using SPSS 23.0 for Windows (IBM SPSS, Armonk, NY, USA).

\section{Results}

Expression of TCTP in CRC tissue is closely correlated with $H M G B 1$ serum concentration in patients with CRC. To investigate whether TCTP and HMGB1 have correlativity in the tumor progression and metastasis of CRC, the present study measured the protein level of TCTP in CRC tissue and the serum concentration of HMGB1 in patients with CRC, and assessed the correlation between them. The representative result of immunohistochemical staining of TCTP is shown in Fig. 1A.
In contrast to the immunoreaction of TCTP in adjacent normal colorectal mucosa or lymph nodes, where it was either absent or barely detectable, the expression of TCTP was markedly increased in carcinoma and metastatic foci in lymph nodes. Significant differences were also found in the comparison of TCTP-staining scores between samples from patients with CRC and controls $(\mathrm{P}<0.001)$. As shown in Fig. 1B, the protein levels of TCTP were detected in CRC samples from patients with CRC (with or without metastasis) and from control subjects with benign polyps. As shown by the immunoblotting analysis, the expression of TCTP was markedly higher in the CRC samples than in the non-tumor samples, and was further elevated in tumors that had undergone metastasis. The average serum levels of HMGB1 detected by ELISA examination in patients with CRC and control subjects are shown in Fig. 1C. The serum concentrations of HMGB1 were significantly higher in patients with non-metastatic CRC than in the control group $(35.443 \pm 3.873$ vs. $14.007 \pm 3.348 \mathrm{ng} / \mathrm{ml})$, and this difference was more evident when the patients developed distant metastasis (mean HMGB1 serum level, $41.682 \pm 4.689 \mathrm{ng} / \mathrm{ml}$ ). As shown in Fig. 1D, there was a positive correlation between serum HMGB1 value and tumor tissue TCTP expression (Pearson's correlation coefficient, 0.935; $\mathrm{P}<0.001$ ). All these 
data suggest there may be a potential interaction between the two important tumor-promoting proteins.

TCTP induces HMGB1 cytoplasmic translocation in LoVo cells and extracellular release from cells. To better understand the functions of TCTP in carcinoma cells, vectors for overexpression or knockdown of the TCTP gene were constructed and stably transfected into LoVo cells. This was followed by investigation of whether alteration of the expression of TCTP elicits variation in the expression and location of HMGB1. The results of the immunofluorescence assay revealed the transportation of HMGB1, as shown in Fig. 2A. The fluorescent staining of HMGB1 was largely confined to the nuclei in parental LoVo cells, and was weak when TCTP was knocked down. By contrast, the signal was redistributed to the cytoplasm following upregulation of the expression of TCTP. The immunoblotting analysis (Fig. 2B) further revealed that the cytoplasmic expression of HMGB1 was significantly increased with the increased expression of TCTP, with a correlation rate of 0.984 .

High cytoplasmic levels of HMGB1 usually occur in the context of active HMGB1 release. To confirm this, the present study measured the level of HMGB1 in the culture medium of LoVo cells transfected with the vectors described above. As shown in the immunoblotting (Fig. 2B), the alteration in the protein level of HMGB1 in the medium was approximately parallel with the change in the expression of TCTP in LoVo cells, which followed a similar pattern to that observed for the expression of HMGB1 in the cytoplasm. Taken together, these results demonstrated that TCTP induced the release of HMGB1 from the nucleus to the cytoplasm and into the extracellular space.

It is reported that LDH can leak into extracellular fluids only when damage to the plasma membrane occurs (23). Therefore, the LDH assay was applied to determine whether TCTP can destroy the integrity of the cellular membrane, thus resulting in the release of HMGB1. As shown in Fig. 2C, transfection with either the TCTP-overexpression or TCTP-knockdown plasmids caused minimal LDH leakage, which showed no significant differences when compared with the control LoVo cells. This result indicated that the TCTP-induced release of HMGB1 was the consequence of cell secretion rather than cell membrane damage.

TCTP triggers NF- $\kappa B$ activation in LoVo cells, which is mediated by HMGBl and its receptors TLR4 and RAGE. As NF- $\mathrm{NB}$ has been revealed as a downstream signaling component of several receptors of HMGB1 $(12,17-19)$, and the behavior of HMGB1 in cancer cells appeared to be influenced by TCTP according to the above experiments, the present study examined whether NF- $\mathrm{NB}$ is also involved in the ТСTP-induced signaling pathway. The expression levels and the activity of $\mathrm{NF}-\kappa \mathrm{B}$ were evaluated in LoVo cells following altering of the gene expression of TCTP. As revealed by the immunoblotting analysis (Fig. 3), compared with the untreated normal control LoVo cells, the overexpression of TCTP reduced the protein level of $\mathrm{I} \kappa \mathrm{B} \alpha$ in the cytoplasm, and simultaneously increased the expression of $\mathrm{NF}-\kappa \mathrm{B}$ p65 subunit in the nucleus $(\mathrm{P}=0.003$ and $\mathrm{P}<0.001$, respectively), indicating a process of proteolytic degradation of $\mathrm{I} \kappa \mathrm{B}$ and nuclear translocation of $\mathrm{NF}-\kappa \mathrm{B}$. By contrast, when the TCTP-overexpressing cells were treated with antibody against HMGB1 $(5 \mu \mathrm{g} / \mathrm{ml}$ for $24 \mathrm{~h})$, the responses

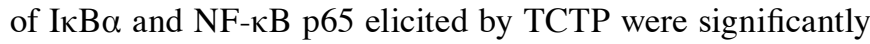
reversed $(\mathrm{P}<0.001)$. Further experiments revealed (Fig. 4A) that the inhibition of HMGB1 by applying antibodies to its receptors TLR4 or RAGE $(5 \mu \mathrm{g} / \mathrm{ml}$ for $24 \mathrm{~h})$ in these cells also led to a reduction of TCTP-induced NF- $\mathrm{BB}$ activation. These findings were consistent with the results of the luciferase assay (Fig. 4B), which showed that the activity of NF- $\kappa \mathrm{B}$ was enhanced by the overexpression of TCTP or administration of rhHMGB1 $(10 \mu \mathrm{g} / \mathrm{ml}$ for $24 \mathrm{~h})$, but decreased by the antagonists of HMGB1. Knockdown of the TCTP gene in LoVo cells led to a similar effect to these antagonisms of HMGB1 on the activation of NF- $\kappa \mathrm{B}$. Taken together, these results indicated that TCTP activated NF- $\mathrm{KB}$ in LoVo cells through the mediation of HMGB1 and its receptors TLR4 and RAGE.

TCTP increases the invasion potential of LoVo cells through activation of the HMGB1-TLR4/RAGE-NF- $\kappa B$ pathway. The present study further investigated the invasive capacity of LoVo cells following the treatments described above. As shown in Fig. 5, compared with the untreated parental LoVo cells, the downregulation of TCTP significantly inhibited the invasion ability of the tumor cells, whereas the upregulation of TCTP led to the opposite result (both $\mathrm{P}<0.001$ ). These three groups of cells were then treated with rhHMGB1 or relevant neutralizing antibodies. The results demonstrated that the increased cell invasiveness induced by TCTP was further promoted by rhHMGB1, but was substantially attenuated by administration of antibodies against HMGB1, TLR4 or RAGE. In addition, treatment with the specific NF- $\kappa \mathrm{B}$ inhibitor Bay117082 (5 $\mu \mathrm{mol} / \mathrm{l})$ significantly suppressed tumor cell invasion. These results indicated that the effect of TCTP on the invasion of LoVo cells was mediated by the HMGB1-TLR4/RAGE-NF- $\kappa \mathrm{B}$ pathway.

TCTP regulates the expression of HMGB1 in xenograft tumors in nude mice. As it was found that the expression of HMGB1 in LoVo cells was regulated by TCTP, a corresponding change in the expression of HMGB1 was anticipated in xenograft tumors in nude mice following modulation of TCTP gene expression. The visualized observations were similar to our previous studies $(7,8)$, which showed that the weight of xenograft tumors and the number of hepatic metastases were synchronously altered with the expression level of TCTP in LoVo cells (data not shown). In addition, the immunostaining density of HMGB1 was positively linked with that of TCTP in primary tumor tissues (Fig. 6A) and in metastatic foci (Fig. 6B), both of which varied in accordance with the gene expression levels of TCTP in the LoVo cells. Further microscopic examinations revealed that the metastatic nodules in mouse livers were significantly augmented with the increased expression of TCTP (Fig. 6B, 'H\&E' panel). There were significant differences in the immunohistochemical staining scores of TCTP and HMGB1 between either the TCTP-overexpression or TCTP-knockdown groups and the control (all $\mathrm{P}<0.05$ ). These findings suggested that TCTP promoted the progression of $\mathrm{CRC}$ and liver metastasis; it also regulated the expression of HMGB1, which possibly produced synergistic effects on the metastatic process of CRC. 


\section{Discussion}

In the present study, it was demonstrated that the expression level of TCTP was significantly increased in CRC tissues, which supports others' and our previous reports $(7,8,24)$. It was found that the serum level of HMGB1 was markedly elevated in patients with CRC, which is consistent with previous reports $(25,26)$. The results also showed that the expression of TCTP and the concentration of HMGB1 were markedly higher in the samples from patients with CRC with distant metastasis, indicating that they are associated with the clinical severity and prognosis of CRC. In addition, it was found that there was a strong positive correlation between the two increased proteins. This is the first time, to the best of our knowledge, that TCTP and HMGB1 have been assessed together in an integrated study to test the hypothesis that they may have an interconnection in the process of tumor progression and metastasis. These preliminary findings provide incentive for further investigation of the interaction between the two tumor-promoting factors.

From the in vitro experiments, it was noted that TCTP induced the cytoplasmic translocation of HMGB1 and its further release into the extracellular environment. These findings support the hypothesis that HMGB1 can be secreted from CRC cells, which has been documented previously $(14,27)$, and provide important novel insight that the secretion of HMGB1 is regulated by TCTP. Furthermore, in xenograft tumors in nude mice, it was found that augmentation of expression of TCTP promoted liver metastasis of CRC cells, which was accompanied by a marked increase in the expression of HMGB1. This finding confirmed that TCTP regulated the behavior of HMGB1, which may produce synergistic effects on the formation and metastasis of CRC.

It appears that, when secreted from cells, HMGB1 becomes a multifunctional cytokine for regulating cell proliferation, survival and migration (12-17). Previous evidence indicates that extracellular HMGB1 is not only involved in chronic inflammatory-reparative responses, which contribute to tumor cell survival and metastasis (27-29), but also induces apoptosis in immune cells, resulting in an attenuation of anticancer immune responses (30). TLR and RAGE, the main receptors of HMGB1, also contribute to the progression and metastasis of CRC (31-35). It has been shown that the HMGB1-TLR-RAGE tripod frequently activates the downstream NF- $\mathrm{KB}$ signaling pathway (17-19), and it has subsequently been demonstrated that dimerized TCTP, the biologically active form of TCTP, can also activate the NF- $\mathrm{kB}$ pathway and induce inflammation (36). However, there is no literature concerning whether the NF- $\mathrm{KB}$ pathway is involved in TCTP-promoted tumor cell invasion and metastasis. The present study provided evidence that TCTP stimulated the activation of NF- $\mathrm{KB}$ in colon adenocarcinoma cells, and that this was abrogated by antibodies against HMGB1, TLR4 or RAGE. These results indicated that TCTP can induce the activation of NF- $\kappa B$ through the mediation of HMGB1 and its receptors TLR4 and RAGE. In addition, it was found that TCTP and the successive activation of the HMGB1-TLR4/RAGENF- $\kappa B$ pathway enhanced the invasion potential of LoVo cells, whereas the specific NF- $\mathrm{\kappa B}$ inhibitor Bayl17082 attenuated the increased invasiveness of tumor cells. This indicated that the activation of NF- $\mathrm{BB}$ signaling is essential for TCTP-mediated tumor cell migration and invasion.
Although experimental studies have revealed the importance of NF- $\mathrm{kB}$ in the initiation and propagation of $\mathrm{CRC}$, the mechanisms underlying how NF- $\mathrm{KB}$ promotes tumor metastasis remain to be fully elucidated. There are several reasons that may account for NF-kB-facilitated tumor metastasis. Firstly, $\mathrm{NF}-\kappa \mathrm{B}$ orchestrates a variety of cellular effectors of inflammation to constitute a local environment that may promote cancer cell invasiveness (37-39). Secondly, NF- $\kappa \mathrm{B}$ upregulates the expression of target genes that are involved in tumor metastasis, for example MMPs $(20,40,41)$. Finally, increasing data suggest that NF- $\mathrm{KB}$ is implicated in the progression of cancer epithelial-to-mesenchymal transition, which is an essential process in the initiation of tumor spread (42-44). Previous studies have indicated that HMGB1 and TCTP can induce epithelial-to-mesenchymal transition and thus promote tumor cell migration and invasion $(31,42,45)$. Therefore, NF- $\kappa \mathrm{B}$ and its upstream and downstream network present a rational target to curb the progression of CRC.

Of note, HMGB1 can be modified posttranslationally in multiple ways, which may in turn determine the location and secretion of HMGB1 and its interactions with DNA and other proteins (46). The discrepancy in bioactivities of HMGB1 may be associated with different cell types or tissue sources, or its responses to different stimuli (47). In addition, TCTP has diverse biological activities on account of its different forms (36), localizations (7) or extracellular environments (2). Therefore, future investigations require that all these factors are taken into consideration, and the design of further investigations requires the use of strategies to inhibit the expression, release or activity of these dynamic proteins for comprehensive assessment of their functions and interactions in regulating tumor progression.

In conclusion, the present study indicated that TCTP affected the behaviors of HMGB1, and facilitated CRC cell invasion via HMGB1-mediated activation of the NF- $\kappa \mathrm{B}$ pathway. These findings provide novel clues for elucidating the mechanism of TCTP-induced metastasis of CRC, and suggest that TCTP can be used as a potential target for anticancer therapy.

\section{Acknowledgements}

The authors would like to thank the staff of Digestive Endoscopy Center of Nanfang Hospital and Department of Pathology, Nanfang Hospital for providing the tissue specimens.

\section{Funding}

This study was supported by the National Natural Science Foundation of China (grant nos. 81000952 and 81772133), the Guangdong Natural Science Fund (grant no. S2013030013217), the Guangdong Natural Science Fund (grant no. 2016A030313529) and the Guangxi Natural Science Fund (grant nos. 2017GXNSFDA198051 and 2016GXNSFAA380313).

\section{Availability of data and materials}

All data generated or analyzed during this study are included in this published article. 


\section{Authors' contributions}

$\mathrm{MH}, \mathrm{QM}$ and YW were involved in the conception and design of the study; MH, YG, QD, QM, RL, XS, ZZ and WX performed the experiments; $\mathrm{MH}, \mathrm{YG}$ and QM analyzed the data; $\mathrm{MH}$ drafted the manuscript; QM and YW reviewed and edited the manuscript. All authors have read and approved the final manuscript.

\section{Ethics approval and consent to participate}

The protocols for the collection of human tissues were approved by the Ethics Committee of Nanfang Hospital, Southern Medical University, and written informed consent was signed by each participant prior to their inclusion in the study. The animal experiment was approved by the Association for the Accreditation and Assessment of Laboratory Animal Care (Guangzhou, China).

\section{Patient consent for publication}

Not applicable.

\section{Competing interests}

The authors declare that they have no competing interests.

\section{References}

1. Siegel R, DeSantis C, Virgo K, Stein K, Mariotto A, Smith T, Cooper D, Gansler T, Lerro C, Fedewa S, et al: Cancer treatment and survivorship statistics, 2012. CA Cancer J Clin 62: 220-241, 2012.

2. Acunzo J, Baylot V, So A and Rocchi P: TCTP as therapeutic target in cancers. Cancer Treat Rev 40: 760-769, 2014.

3. Amson R, Pece S, Marine JC, Di Fiore PP and Telerman A: TPT1/ TCTP-regulated pathways in phenotypic reprogramming. Trends Cell Biol 23: 37-46, 2013.

4. Chan TH, Chen L and Guan XY: Role of translationally controlled tumor protein in cancer progression. Biochem Res Int 2012: 369384, 2012.

5. Amson R, Pece S, Lespagnol A, Vyas R, Mazzarol G, Tosoni D, Colaluca I, Viale G, Rodrigues-Ferreira S, Wynendaele J, et al: Reciprocal repression between P53 and TCTP. Nat Med 18 91-99, 2011.

6. Chan TH, Chen L, Liu M, Hu L, Zheng BJ, Poon VK, Huang P, Yuan YF, Huang JD, Yang J, et al: Translationally controlled tumor protein induces mitotic defects and chromosome missegregation in hepatocellular carcinoma development. Hepatology 55: 491-505, 2012.

7. Xiao B, Chen D, Luo S, Hao W, Jing F, Liu T, Wang S, Geng Y, Li L, $\mathrm{Xu}$ W, et al: Extracellular translationally controlled tumor protein promotes colorectal cancer invasion and metastasis through Cdc42/JNK/ MMP9 signaling. Oncotarget 7: 50057-50073, 2016.

8. Ma Q, Geng Y, Xu W, Wu Y, He F, Shu W, Huang M, Du H and $\mathrm{Li} \mathrm{M}$ : The role of translationally controlled tumor protein in tumor growth and metastasis of colon adenocarcinoma cells. J Proteome Res 9: 40-49, 2010

9. Ueda M, Takahashi Y, Shinden Y, Sakimura S, Hirata H, Uchi R, Takano Y, Kurashige J, Iguchi T, Eguchi H, et al: Prognostic significance of high mobility group box 1 (HMGB1) expression in patients with colorectal cancer. Anticancer Res 34: 5357-5362, 2014.

10. Zhang Z, Wang M, Zhou L, Feng X, Cheng J, Yu Y, Gong Y, Zhu Y, Li C, Tian L, et al: Increased HMGB1 and cleaved caspase-3 stimulate the proliferation of tumor cells and are correlated with the poor prognosis in colorectal cancer. J Exp Clin Cancer Res 34: $51,2015$.

11. Süren D, Yıldırım M, Demirpençe Ö, Kaya V, Alikanoğlu AS, Bülbüller N, Yıldız M and Sezer C: The role of high mobility group box 1 (HMGB1) in colorectal cancer. Med Sci Monit 20 : 530-537, 2014.
12. van Beijnum JR, Buurman WA and Griffioen AW: Convergence and amplification of toll-like receptor (TLR) and receptor for advanced glycation end products (RAGE) signaling pathways via high mobility group B1 (HMGB1). Angiogenesis 11:91-99, 2008.

13. Dumitriu IE, Baruah P, Valentinis B, Voll RE, Herrmann M, Nawroth PP, Arnold B, Bianchi ME, Manfredi AA and Rovere-Querini P: Release of high mobility group box 1 by dendritic cells controls $\mathrm{T}$ cell activation via the receptor for advanced glycation end products. J Immunol 174: 7506-7515, 2005.

14. Kang HJ, Lee H, Choi HJ, Youn JH, Shin JS, Ahn YH, Yoo JS, Paik YK and Kim H: Non-histone nuclear factor HMGB1 is phosphorylated and secreted in colon cancers. Lab Invest 89: 948-959, 2009

15. Lee W, Ku SK, Bae JW and Bae JS: Inhibitory effects of lycopene on HMGB1-mediated pro-inflammatory responses in both cellular and animal models. Food Chem Toxicol 50: 1826-1833, 2012.

16. Sims GP, Rowe DC, Rietdijk ST, Herbst R and Coyle AJ: HMGB1 and RAGE in inflammation and cancer. Annu Rev Immunol 28: 367-388, 2010.

17. Nogueira-Machado JA and de Oliveira Volpe CM: HMGB-1 as a target for inflammation controlling. Recent Pat Endocr Metab Immune Drug Discov 6: 201-209, 2012.

18. Nogueira-Machado JA, Volpe CM, Veloso CA and Chaves MM: HMGB1, TLR and RAGE: A functional tripod that leads to diabetic inflammation. Expert Opin Ther Targets 15: 1023-1035, 2011

19. Li Y, He J, Zhong D, Li J and Liang H: High-mobility group box 1 protein activating nuclear factor- $\mathrm{\kappa B}$ to upregulate vascular endothelial growth factor $\mathrm{C}$ is involved in lymphangiogenesis and lymphatic node metastasis in colon cancer. J Int Med Res 43: 494-505, 2015.

20. Wang S, Liu Z, Wang L and Zhang X: NF-kappaB signaling pathway, inflammation and colorectal cancer. Cell Mol Immunol 6: 327-334, 2009.

21. Raina K, Agarwal $C$ and Agarwal R: Effect of silibinin in human colorectal cancer cells: Targeting the activation of NF- $\mathrm{KB}$ signaling. Mol Carcinog 52: 195-206, 2013.

22. Chang MS, Kim DH, Roh JK, Middeldorp JM, Kim YS, Kim S, Han S, Kim CW, Lee BL, Kim WH, et al: Epstein-Barr virusencoded BARF1 promotes proliferation of gastric carcinoma cells through regulation of NF- $\kappa$ B. J Virol 87: 10515-10523, 2013.

23. Shafiu Kamba A and Zakaria ZA: Osteoblasts growth behaviour on bio-based calcium carbonate aragonite nanocrystal. BioMed Res Int 2014: 215097, 2014.

24. Bommer UA, Vine KL, Puri P, Engel M, Belfiore L, Fildes K, Batterham M, Lochhead A and Aghmesheh M: Translationally controlled tumour protein TCTP is induced early in human colorectal tumours and contributes to the resistance of HCT116 colon cancer cells to 5-FU and oxaliplatin. Cell Commun Signal 15: 9, 2017.

25. Zhang X, Yu J, Li M, Zhu H, Sun X and Kong L: The association of HMGB1 expression with clinicopathological significance and prognosis in Asian patients with colorectal carcinoma: A meta-analysis and literature review. OncoTargets Ther 9: 4901-4911, 2016.

26. Lee H, Song M, Shin N, Shin CH, Min BS, Kim HS, Yoo JS and Kim H: Diagnostic significance of serum HMGB1 in colorectal carcinomas. PLoS One 7: e34318, 2012.

27. Luo Y, Chihara Y, Fujimoto K, Sasahira T, Kuwada M, Fujiwara R, Fujii K, Ohmori H and Kuniyasu H: High mobility group box 1 released from necrotic cells enhances regrowth and metastasis of cancer cells that have survived chemotherapy. Eur J Cancer 49: 741-751, 2013

28. Tang D, Kang R, Zeh HJ III and Lotze MT: High-mobility group box 1 and cancer. Biochim Biophys Acta 1799: 131-140, 2010.

29. Chen RC, Yi PP, Zhou RR, Xiao MF, Huang ZB, Tang DL, Huang Y and Fan XG: The role of HMGB1-RAGE axis in migration and invasion of hepatocellular carcinoma cell lines. Mol Cell Biochem 390: 271-280, 2014

30. Völp K, Brezniceanu ML, Bösser S, Brabletz T, Kirchner T, Göttel D, Joos S and Zörnig M: Increased expression of high mobility group box 1 (HMGB1) is associated with an elevated level of the antiapoptotic c-IAP2 protein in human colon carcinomas. Gut 55: 234-242, 2006.

31. Sharma S, Evans A and Hemers E: Mesenchymal-epithelial signalling in tumour microenvironment: Role of high-mobility group Box 1. Cell Tissue Res 365: 357-366, 2016.

32. Han M, Song Y and Zhang X: Quercetin suppresses the migration and invasion in human colon cancer Caco-2 cells through regulating toll-like receptor 4/nuclear factor-kappa B pathway. Pharmacogn Mag 12 (Suppl 2): S237-S244, 2016. 
33. Yesudhas D, Gosu V, Anwar MA and Choi S: Multiple roles of toll-like receptor 4 in colorectal cancer. Front Immunol 5: 334, 2014.

34. Deng R, Wu H, Ran H, Kong X, Hu L, Wang X and Su Q: Glucose-derived AGEs promote migration and invasion of colorectal cancer by up-regulating Sp1 expression. Biochim Biophys Acta 1861: 1065-1074, 2017.

35. Dahlmann M, Okhrimenko A, Marcinkowski P, Osterland M, Herrmann P, Smith J, Heizmann CW, Schlag PM and Stein U: RAGE mediates S100A4-induced cell motility via MAPK/ERK and hypoxia signaling and is a prognostic biomarker for human colorectal cancer metastasis. Oncotarget 5: 3220-3233, 2014.

36. Lee $\mathrm{H}$ and Lee K: Dimerized translationally controlled tumor protein increases interleukin-8 expression through MAPK and NF- $\kappa B$ pathways in a human bronchial epithelial cell line. Cell Biosci 8: 13, 2018.

37. Karin $M$ and Greten FR: NF-kappaB: Linking inflammation and immunity to cancer development and progression. Nat Rev Immunol 5: 749-759, 2005.

38. Mantovani A, Allavena P, Sica A and Balkwill F: Cancer-related inflammation. Nature 454: 436-444, 2008.

39. Vaiopoulos AG, Athanasoula KC and Papavassiliou AG: NF-кB in colorectal cancer. J Mol Med (Berl) 91: 1029-1037, 2013.

40. Chen S, Chen W, Zhang X, Lin S and Chen Z: Overexpression of KiSS-1 reduces colorectal cancer cell invasion by downregulating MMP-9 via blocking PI3K/Akt/NF- $\mathrm{KB}$ signal pathway. Int J Oncol 48: 1391-1398, 2016.

41. Qin M, Liu S, Li A, Xu C, Tan L, Huang J and Liu S: NIK- and IKK $\beta$-binding protein promotes colon cancer metastasis by activating the classical NF- $\mathrm{BB}$ pathway and MMPs. Tumour Biol 37: 5979-5990, 2016.
42. Zhu L, Li X, Chen Y, Fang J and Ge Z: High-mobility group box 1: A novel inducer of the epithelial-mesenchymal transition in colorectal carcinoma. Cancer Lett 357: 527-534, 2015.

43. Ma J, Gao Q, Zeng S and Shen H: Knockdown of NDRG1 promote epithelial-mesenchymal transition of colorectal cancer via NF- $\kappa B$ signaling. J Surg Oncol 114: 520-527, 2016.

44. Yan Z, Yin H, Wang R, Wu D, Sun W, Liu B and Su Q: Overexpression of integrin-linked kinase (ILK) promotes migration and invasion of colorectal cancer cells by inducing epithelial-mesenchymal transition via NF- $\mathrm{BB}$ signaling. Acta Histochem 116: 527-533, 2014.

45. Bae SY, Kim HJ, Lee KJ and Lee K: Translationally controlled tumor protein induces epithelial to mesenchymal transition and promotes cell migration, invasion and metastasis. Sci Rep 5: $8061,2015$.

46. Richard SA, Jiang Y, Xiang LH, Zhou S, Wang J, Su Z and Xu H: Post-translational modifications of high mobility group box 1 and cancer. Am J Transl Res 9: 5181-5196, 2017.

47. Huebener P, Pradere JP, Hernandez C, Gwak GY, Caviglia JM, Mu X, Loike JD, Jenkins RE, Antoine DJ and Schwabe RF: The HMGB1/RAGE axis triggers neutrophil-mediated injury amplification following necrosis. J Clin Invest 125: 539-550, 2015.

This work is licensed under a Creative Commons Attribution-NonCommercial-NoDerivatives 4.0 International (CC BY-NC-ND 4.0) License. 